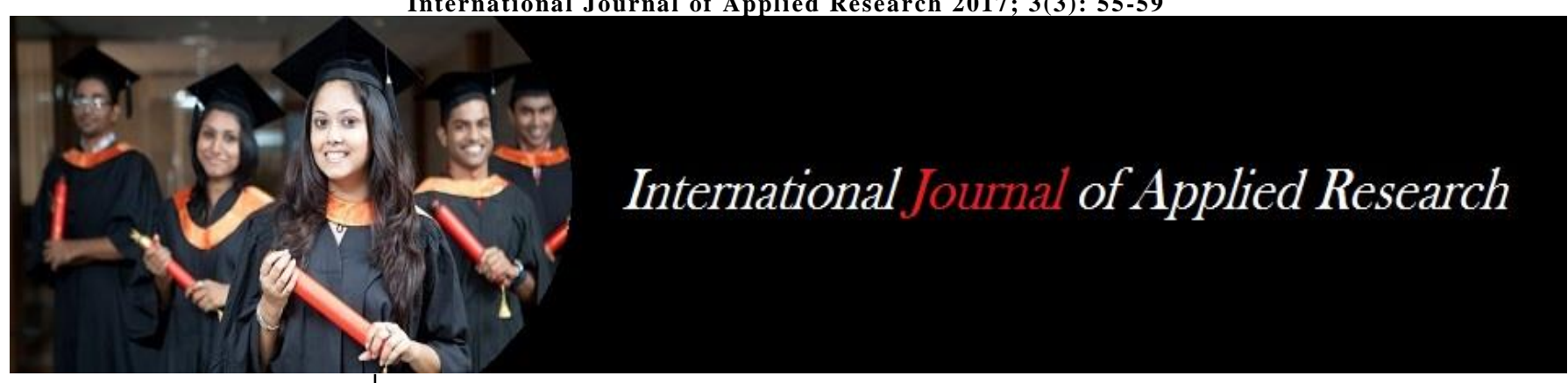

ISSN Print: 2394-7500 ISSN Online: 2394-5869 Impact Factor: 8.4

IJAR 2017; 3(3): 55-59 www.allresearchjournal.com

Received: 18-01-2017 Accepted: 21-02-2017

\section{पूनम कुमारी}

इतिहास विभाग, ल० ना० मिथिला विश्वविद्यालय, दरभंगा, बिहार, भारत।
Corresponding Author: पूनम कुमारी इतिहास विभाग, ल० ना० मिथिला विश्वविद्यालय, दरभंगा, बिहार भारत।

\section{बिहार स्वाधीनता आन्दोंलन में काँग्रेस और मुस्लिमलीग की सत्ता के साथ अँग्रेजों का सौदेबाजी}

\section{पूनम कुमारी}

DOI: https://doi.org/10.22271/allresearch.2017.v3.i3a.7481

\section{सारांश}

15 अगस्त 1947 के अंतर्विरोध आज तक इतिहासकारों को हैरान कर रहे हैं। सीमा के दोनों ओर के लोगों को भी उनके नतीजों से मुक्ति नहीं मिल पाई है। आजादी एक लम्बे, गौरवपूर्ण संघर्ष के बाद हासिल की गई थी और इससे करोड़ो लोगों का सपना पूरा हुआ था। लेकिन उसके साथ ही एक खूनी त्रासद विभाजन ने हमारे उदीयमान स्वतंत्र राष्ट्र के ताने-बाने को छिन्न-भिन्न कर दिया। इस संदर्भ में दो महत्वपूर्ण सवाल उठते है। अंग्रेजों ने अततः भारत क्यों छोड़ा ? विभाजन की योजना कांग्रेस ने क्यों स्वीकार की ? इन सवालों का साम्राज्यवादी जवाब बहुत सीधा-सादा है। ब्रिटेन चाहता था कि भारतीय अपना शासन खुद चलाएँ और आजादी उसकी इसी इच्छा का नतीजा थी। विभाजन सदियों पुराने हिन्दु-मुसलिम वैमनस्य का दुर्भाग्यपूर्ण परिणाम था, इस बात का सबतत यह है कि ये दोनों समुदाय आपस में तय नहीं कर पाए कि सत्ता किसे सौपी जाए और कैसे ? साम्यवादी मानते है कि आजादी 1946-47 के उन जन-सघर्षो द्वारा हासिल की गई, जिनमें बहुत से कम्युनिस्टों ने योगदान किया और अनेक मोकों पर जिनका नेतृत्व भी किया। लेकिन कांग्रेस के बुर्जुआ नेता इस क्रांति उभार से डर गए और उन्होंने साम्राज्यवादियों से समझौता कर सत्ता अपने हाथ में ले ली। राष्ट्र को इसकी कीमत विभाजन के रूप में चुकानी पड़ी।

\section{प्रस्तावना}

बिहार में 1945 से कम्युनिस्ट आन्दोंलन को और गति मिली। जिससे बिहार में राजेन्द्र प्रसाद तथा अन्य कांग्रेस नेताओं के अथक प्रयास के फलस्वरूप निवार्चन में कांग्रेस विजयी रही। दिसंम्बर 1945 ई0 में केद्रीय धारा सभा में 10 स्थानों में कांग्रेस को 6 स्थान मिले। मार्च 1946 ई0 तक चुनाव की सरगर्मी शांत हो गई। बिहार की धारा सभा के निम्न सदन या विधान सभा के 152 सदस्यों की दलगत स्थिति निम्न थी। 1

कांग्रेस-—-—-98

मुस्लिम लीग--—-34

मोमिन---—- 5

आदिवासी-—- 3

निर्दलीय - - 12

30 मार्च 1946 ई0 को बिहार के गवर्नर ने श्रीकृष्ण सिंह को मंत्रिमंडल निर्माण के लिए अमंत्रित किया श्री कृष्ण सिंह, अनुग्रह नारायण सिंह और सैयद महमूद ने ग्यारह बजे शपथ ली। जगलाल चौधरी को रिहा कर दिया गया। वे भी मंत्रिमंडल में शमिल किए गए कुछ ही दिनों में मंत्रिमण्डल का विस्तार किया गया। राम चरित्र सिंह, आचार्य बद्रीनाथ वर्मा कृष्ण बल्लभ सहाय पंडित विनोदानंद झा और अब्दुल क्यूम अंसारी को भी शामिल किया गया।

12 अप्रैल को सरकार ने कांग्रेस सोशलिस्ट पार्टी पर से प्रतिबंध उठा दिया था। जयप्रकाश नारायण की मुक्ति की सवों ने स्वागत किया। पटना आने पर उनका भव्य स्वागत किया गयां। फारवार्ड ब्लॉक सरकार से तालमेल नहीं बैठा सका। मार्च-अप्रैल में अरंविद बोस ने मुंगेर, पटना, मुजफ्फरपुर और दरभंगा जिलों का दौरा किया। बिहार फारवार्ड ब्लॉक के नेता शीलभद्र याजी भी सक्रिय थे। अब तक यह स्पष्ट हो चुका था कि भारत की आजादी में अब देर नहीं। 1946 ई0 में गाँधीजी ने कहा, "भारत आजादी की ओर बढ़ रहा है। भले ही कांग्रेस और मुस्लिम लीग में समझौता हो या न हो। स्वतंत्रता भारत के भाग्य में हैं। इसके लिए इसने काफी कुर्बानी दी है।" ब्रिटिश प्रधानमंत्री क्लीमेंट एटली ने 15 मार्च, 1946 ई० को कहा, “1946 का वर्ष 1920 ई0 का वर्ष नहीं है। इस समय भारत ही नहीं पूरा एशिया राष्ट्रीयता की लहर से ओतप्रोत है। 
"ब्रिटिश सरकार ने भारत में कैबिनेट मिशन भेजा। इसमें 'भारत मंत्री लार्ड पैथिक लारेंस, व्यापार पर्षद का अध्यक्ष सर स्टाफर्ड क्रिप्स और ए0 वी० अलेक्जेंडर थे। कैबिनेट मिशन के मुख्य प्रस्ताव थे (क) भारत संघ का निर्माण जिसमें ब्रिटिश भारत और देशी राज्य होंगे। संघ के अधीन विदेशी मामले, प्रतिरक्षा, परिवहन और संचार होंगे (ख) प्रांतो को ए, बी और सी समूहों में बाटना। (ग) संविधान निर्मात्री सभा को बुलाना। भारत के किसी दल ने कैबिनेट मिशन के प्रस्तावों को स्वीकार नहीं किया।

देश में सांप्रदायिक दंगा बहुत जोर पकड़ रहा था। ब्रिटिश सरकार ने यह अनुभव किया कि भारत की स्थिति अब उसके नियंत्रण में नहीं है। उसने भारत के भाग्य को उसकी जनता के हाथों में छोड़कर चले जाने का निश्चय किया। ब्रिटिश सरकार ने लार्ड वेवेल को वापस बुला लिया और उसके स्थान पर लार्ड माउट बटन दिल्ली पहुँचे। भारतीय नेताओं से विचार-विमर्श करने के पश्चात् मई में वे इंग्लैंड गए और वहाँ से वापस आने पर 3 जून 1947 ई0 को एक योजना निकाली जो माउंट बेटन योजन के नाम से प्रसिद्ध है। मुस्लिम लीग ने शीध्र ही इसे स्वीकार कर लिया क्योंकि इससे उसको पाकिस्तान मिल रहा था। कांग्रेस ने भी सदा अखंड भारत का समर्थन किया था, देश की स्थिति की पृष्टभूमि में इसे स्वीकार कर लिया। माउंट वेटन योजना के आधार पर ब्रिटिश संसद में 4 जुलाई को एक बिल पेश किया गया। 18 जुलाई को यह विधेयक स्वीकृत हो गया। इसके द्वारा यह निश्चित किया गया कि 15 अगस्त 1947 ई0 को भारत और पाकिस्तान नामक दो स्वतंत्र राज्यों की स्थापना होगी और उन दोनों को औपनिवेशिक पद प्रदान किया जाएगा। ${ }^{2}$

\section{मूल स्त्रोत}

बिहार राज्य आभिलेखागार, पटना, साक्षात्कार का तथ्य एवं आधुनिक बिहार का इतिहास से संम्बधित विषय के पुस्तकों से साक्ष्यों और तथ्यों का संकलंन किया है।

एक ओर काँग्रेस और लीग नेता अँग्रेजो के साथ सत्ता की सौदेबाजी में लगे थे तो दूसरी ओर भारतीय कम्युनिस्ट पार्टी जन आन्दोलन के बल पर सत्ता हस्तान्तरण नहीं बल्कि पूर्ण स्वाधीनता हासिल करना चाहती थी इससे ब्रिटिश शासन, काँगेस और लीग तीनों बौखला उठे। जनबरी 1947 में सारे देश में कम्युनिस्ट पार्टी के नेताओं और कार्यकर्त्ता को गिरफ्तारी शुरू की गयी। सरदार पटेल ने केन्द्रीय सरकार के गृहमंत्री की हैसियत से बड़े गर्व के साथ इन गिरफ्तारियों की जिम्मेदारी आपने ऊपर ली। उन्होंने 21 फरवरी,1947 को केन्द्रीय विधानसभा में वक्तव्य देकर सूचित किया कि 1950 कम्युनिस्ट गिरफ्तार किये गये हैं। ${ }^{3}$

1946 के उतरार्द्ध में भारतीय कम्युनिस्ट पार्टी के नेतृत्व में बिहार में बड़े पैमाने पर किसान आन्दोलन शुरू किया गया। इस किसान आन्दोलन में मुख्य रूप से बकास्त जमीन की वापसी, बटाईदारी एवं जमींदारी उन्मूलंन के सवाल मुख्य थे। बिहार के कई जिलों में आन्दोलंन ने वृहद रूप ले लिया।" दरभंगा में तो किसान आंदोलंन इतने बड़े पैमाने पर फैलाकि जमींदारों ने बौखलाकर श्री भोगेन्द्र झा पर कातिलाना हमला करवा दिया। जमींदार के लठैतो ने हथियारों के साथ भोगेन्द्र झा की हत्या के ख्याल से ही हमला किया था। भोगेन्द्र झा काफी जख्मी हो गये। उनके दो साथी श्री पलटु यादव एवं श्री संत खतवें ने जो जमींदारों के लठेतों से लड़ने एवं भोगेन्द्र झा को बचाने में अपनी जान ही गँवा दी। यह घटना 4 जनवरी, 1947 की थी। " किसान आन्दोलन के तहत लड़नेवाले एवं स्वाधीनता की लड़ाई में भाकपा के बिहार में प्रथम शहीद थे। पलटू यादव एवं संत खतबे भोगेन्द्र झा के बहुत अच्छे सहयोगी थे। कर्मठ कम्युनिस्ट कार्यकर्ता थे। किसान आन्दोलन को उस क्षेत्र मे आगे बढ़ाने में उनकी अहम भूमिका थी। वैसे एक कम्युनिस्ट के रूप में मजदूर आन्दोंलन के तहद् शहीद हानेवाले प्रथम शहीद जमशेदपुर के श्री हजारा सिंह थे, जिनकी हत्या टाटा ने करवायी थी। ये अन्डामान
जेल में ही कम्युनिस्ट बन चुके थे। जिसका दूसरे अध्याय में उल्लेख किया जा चुका है।

1947 के उतरार्द्ध में भोगेन्द्र झा की हत्या के प्रयास के बाद किसान आन्दोंलन पुराना दरभंगा जिला में तीव्र हो उठा। साथ ही सरकारी दमन का सिलसिला भी तेज हो गया। परिणामस्वरूप भोगेन्द्र झा, तेज नारायण झा इत्यादि गिरफ्तार कर लिये गये। जेल की कालकोठरी में फिर इन क्रांतिकारियों को जाना पड़ा। पुराने मुंगेर जिले में भी किसान आन्दोंलन ने जोर पकड़ा। कई स्थानों पर जमींदारों के लठैतों से मुठभेंड़ हुई। बड़हिया, चानन इलाकों में तो किसान आन्दोलन इतना तीव्र हो गया कि जमीदारों को किसानों के सामने झुकना पड़ा था। किसानों ने जमींदारों द्वारा दखल बकास्त भूमि फिर से अपने कब्जे में लेली। ${ }^{6}$ किसान आन्दोलंन को कुचलने के लिए यहाँ भी गिरफ्तार किये गये। कई स्थानों पर लाठी चार्ज करवाया गया। आम सभाओं पर पाबन्दी लगायी गयी, लेकिन आन्दोंलन दिन प्रतिदिन तेज ही होता चला गया।

सरकारी दस्तावेजों से पता चलता है कि दरभंगा ओ० टी० रेलवे में हाल ही में कुछ मजदूरों की बहाली हुई थी। ये मजदूर कम्युनिस्ट सिद्धान्तों एवं नीतियों से प्रभावित थे। रेलवे प्रबंधन को इन कम्युनिस्टों से सर्तक रहने को कहा गया था। 1947 के शुरूआती दौर में भारत के कई राज्यों सहित बिहार में भी साम्प्रदायिक दंगे बड़े पैमाने पर हुए थे। दरभंगा कम्युनिस्ट पार्टी को जिला कमिटी की बैठक हुई जिसमें साम्प्रदायिक दंगों पर गंभीरता से सर्तक रहने की अपील की गयी। इतना ही नहीं इन कम्युनिस्टों ने साम्प्रदायिक दंगों को रोकेने एवं अन्य राहत कार्य करने में अहम् भूमिका निभायी। खासकर ए० आई० एस० एफ० के कार्यकर्त्ताओं ने इसमें बढ़ चढ़कर भाग लिया।

भारतीय कम्युनिस्ट पार्टी की पटना जिला इकाई का सम्मेलन दीनापुर (अब के दानापुर को उस काल में दीनापुर कहा जाता था क्योंकि इस तरह के शब्द का प्रयोग सरकारी दस्तावेज में किया गया हैं) में हुआ। सम्मेलन की अध्यक्षता श्री ज्ञान विकास मित्रा ने की। सम्मेलन में वक्ताओं ने "कार्यकर्ताओं से नेहरू सरकार को मदद देने की अपील की, क्योंकि जन समर्थन के बल पर ही नेहरू सरकार जमीदारी प्रथा को खत्म कर सकती है या फिर कालाबाजरी करने वालों पर लगाम लगा सकती है। ${ }^{8}$ इसका मतलब यह कदापि नही था कि नेहरू सरकार को समर्थन या मदद के नाम पर पार्टी ने अपने जनआन्दोंलन को कम कर दिया। कम्युनिस्ट पार्टी जनआन्दोलन को तीव्र से तीब्रतर करने का भरसक प्रयास करती रही।

16 फरवरी 1947 को वेगूसराय के मुंगेर जिले में कम्युनिस्टों की एक बैठक हुई। बैठक पार्टी दफ्तर कंपाउंड में ही श्री ब्रह्यदेव सिंह की अध्यक्षता में हुई। इस बैठक में सरकारी ऑकड़ों के अनुसार 300 कम्युनिस्ट कार्यकर्ताओं का जत्था बैठक में आया था।

कम्युनिस्ट कार्यकर्ताओं की संख्या से ऐसा लगता है कि ये कोई साधारण बैठक नही वरन् कम्युनिस्ट कार्यकर्ताओ का कन्वेंशन या सम्मेलन हो रहा हो । इसमें सर्व सम्मति से फैसला लेकर काँग्रेस मंत्रिमंडल की तीव्र आलोचना की गयी एवं आम जनता का अह्वान किया गया कि क्रांति करे और तेज करें। इसी के सहारे ब्रिटिश हुकूमत को उखाड़ फेका जा सकता है और स्वाधीनता हासिल की जा सकती है। अन्य संकट पर विचार करते हुए कहा गया कि काँग्रेस के नाताओं एवं कार्यकर्त्ताओं ने अपने लिए राशन का अधिक कोटा ले रखा है जिसके चलते आम लोगों तक राशन नहीं पहुँच पा रहा है। बाबू श्रीकृष्ण सिंह के स्वागत पर हुए अनावश्यक खर्चो की भी सम्मेलन में तीखी आलोचना की गयी, जो पिछले दिनों इस इलाके को देखने एवं जॉच पड़ताल के लिए आये हुए थे। उनके स्वागत में हजारों रूपये अनावश्यक रूप से खर्च किये गये थे। जमींदारी खत्म करने के प्रश्न पर बातचीत में श्रीकृष्ण सिंह ने कहा "बकास्त जमीन सही मामले में किसानों की 
है जिस पर जमींदारों ने अपना अधिकार बना रखा है। इस संबंध में वे प्रधानमंत्री से बात करेंगे।"9 इस बार शासन हम करेंगे," "जमींदारी प्रथा नाश हो" एवं अन्य कांतिकारी नारों के साथ कन्वेंशन समाप्त हो गया।

ए० आई० टी० यू० की केन्द्रीय की बैठक एवं राष्ट्रव्यापी मजदूर आंदोलन:-

16 जनवरी, 1947 को ए0 आई० टी० यू० सी० की केन्द्रीय कमिटी की बैठक हुई थी। बैठक में मजदूरी की समस्याओं के समाधान हेतु 18 मार्च, 1947 को पूरे भारत मे माँग दिवस मनाने का निर्णय लिया गया था।

उक्त निर्णयानुसार बाँकीपुर में सी० पी० आई० द्वारा 18 मार्च 1947 को आम सभा का आयोजन किया गया । आम सभा की अध्यक्षता ज्ञान विकास मैत्रा ने की। श्री मैत्रा ने सभा को संबोधित करते हुए बताया क " माँग दिवस का अह्वान भारत के सबसे बड़े मजदूर संगठन ए० आई० टी० यू० सी० के द्वारा किया गया था जिसके नेतृत्व में पिछले वर्ष 2,500 हड़ताले हुई थी। इसके तहत पूरे भारत में 700 यूनियनें है तथा इसकी सदस्य संख्या 8 मिलियन है। केवल बिहार में पिछले वर्ष 70 हड़तालें की गई।10 इन्होंने आगे कहा कि "ब्रिटिश सरकार एवं वर्तमान जनता द्वारा चुनी सरकार पूँजीपतियों की कठपुतली है। मजदूरों को पिछले वर्ष कई बार बैलट एवं बुलेट का सामना करना पड़ा।" उन्होंने अंत में मजदूरों से अपील की कि वे सभी ए० आई० टी० यू० सी० के तहत चलनेवाली यूनियनों की सदस्यता ग्रहण करें एवं अपनी यूनियन को ए० आई० टी० यू० से सम्बन्ध करवायें। सरकार को चेतावनी देते हुए श्री मैत्ता ने एलान किया कि यदि सरकार मजदूरों की माँग दिवस की मॉगों को नहीं मानती है तो बाध्य होकर पूरे भारत में एक दिन की आम हड़तानल की जाएगी।

बिहार प्रदेश ट्रेड यूनियन काँग्रेस के विख्यात नेता हबीबुर्रहमान ने केन्द्रीय सरकार द्वारा दो कानून बनाने की तीखी आलोचना की। उन्होंने बतलाया कि " एक कानून के तहत हड़ताल को सरकार अवैध घोषित करती है एवं दूसरे कानून के तहत हड़तालियों को मिलीटरी से कुचलवाया जाता है।"11 उन्होंन मजदूरों को अह्वान किया कि ऐसे कानूनों को जला दो, साथ ही ऐसे कानून बनाने वाली सरकार को भी जलाकर राख कर देना चाहिए। उपर्युक्त नेताओं के अलावा बिजली यूनियन के हरदेव सिंह, बैंक कर्मचारी यूनियन के श्री वाजपेयी, कर्मचारी यूनियन के श्री शिवनन्दन प्रसाद एवं कलकत्ता ट्राम्बे यूनियन के एक नेता ने भी सभी को संबोधित किया।

भारतीय कम्युनिस्ट पार्टी की बिहार प्रदेश कमिटी ने अपनी सभी जिला कमिटीयों को भ्रष्टाचारी अधिकारियों जमाखोरों एवं कालाबाजारी करने वालों के खिलाफ जबरदस्त मुहिम चलाने का निदेश दिया ताकि अकाल से ग्रस्त जनता को कुछ राहत पहुँचायी जा सके। इसके साथ ही बिना किसी मुआवजे के जमींदारी व्यवस्था खत्म करने की माँग की गयी।बकास्त जमीन हो या बटाई जमीन, किसी जमीन के लिए जमींदारों को मुआवजा नहीं मिलना चाहिए। उन जमीनों पर किसानों को अपना कब्जा कर लेना चाहिए ताकि बाढ़, अकाल इत्यादि से जनता को बचाया जा सके। पार्टी ने अपने निर्देश में लिखा था "यदि सरकार अकाल और महामारी से जनता की रक्षा करने में असफल सिद्ध है, तो आम जनता को इन सवालों के साथ जमीदारी उमूलंन के लिए क्रांतिकारी समाधान की ओर बढ़ना चाहिए।" 12 इस अभियान को और तेज करने के लिए पार्टी कार्यकर्त्ताओं की जबरदस्ती जमाखोरों एवं चोरबजारी करने वालों के गोदामों से जमींदारों के अन्न गोदामों से माल निकालकर, जनता में नियंत्रित मूल्य पर बेचने का निर्देश दिया।

मुजफ्फरपुर में कम्युनिस्ट पार्टी ने जमींदारी उन्मूलन के लिए जोरदार सघर्ष का आह्वान किया। परिणामस्वरूप सर्वप्रथम राय बहादुर श्यामानन्दन सहाय की जमींदारी पर किसानों ने धावा
बोल दिया। किसानों ने बकास्त जमीनों पर कब्जा करना शुरू किया। बटाईदारी के खिलाफ आन्दोलंन तेज हो गयी।

पार्टी की प्रान्तीय कमिटी ने भाकपा मानभूम जिला (अब धनवाद) को एक गुप्त निदेश भेजा था। इस निर्देश में पार्टी संगठन के ढ़ाँचे, जुझारू कार्यकर्त्ताओं को पार्टी में शामिल करने इत्यादि की बातें थी। इसके साथ ही 11,12 एवं 13 अप्रैल, 1947 को मानभूम जिला भाकपा का सम्मेलन करने की बात कही गयी थी। सम्मेलन की विशेष जिम्मेवारी जगन्नाथ सरकार को दी गयी थी। निश्चित तिथि को पार्टी का मानभूम जिला सम्मेलन संपन्न हुआ। भाकपा बर्द्धमान जिला कमिटि के नेता श्री मोहन ने भी सम्मेलन में भाग लिया। सर्वसम्मति से सी०पी०आई० के मातहत यूनियन को चलाने के लिए अध्यक्ष मोहन सिंह, उपाध्यक्ष साहदूल मिस्त्री, सचिव सुनिल घोष एवं सह सचिव मुखर्जी चुने गये। मजदूरों ने "इन्कालाब जिन्दाबाद ", "लाल झंडे की जय" एवं "मजदूर राज्य कायम हो" का नारा लगाया। 13

बिहार में 18 मार्च,1947 की ए0आई०टी० य० सी० द्वारा मानाये गये " मॉग दिवस" एवं कम्युनिस्टों को गतिविधियों के संबंध में बिहार गुप्तचर विभाग ने समीक्षा रिपोर्ट तैयार की। समीक्षाके अनुसार "सी० पी० आई0 के कार्यकर्ताओं ने कई स्थानों पर प्रदर्शन किये एवं जुलूस निकाले। कॉलेज शिक्षकों एवं कर्मचारियों ने भी इससे भाग लिया मगर इनकी संख्या बहुत अधिक नहीं थी। ${ }^{14}$

भाकपा ने पुलिस हड़ताल में बिहार में अग्रणी भूमिका निभायी। सर्वप्रथम भाकपा ने पुलिस हड़ताल में अपना समर्थन दिया और उसके सदस्यों ने खुलेआम जुलूस में भाग लिया। मगर कुछ की गिरफ्तारी के बाद एवं सरकारी दमन के बाद भाकपा ने भूमिगत रूप से काम करना शुरू कर दिया। एक समीक्षा में गुप्तचर विभाग ने लिखा "कम्युनिस्टों ने 18.03.1947 को कुस्तौर नवाडीह, अलकूसा, कुसुन्डा एवं भौरा कोलियरी (धनवाद), बाटा शू फैक्टरी, पटना, एम०ई०एस० के दानापुर कैन्ट के कर्मचारियों, गैर सरकारी कॉलेज शिक्षकों के द्वारा पुलिस विद्वोह समर्थन के लिए हड़ताल करवायी। ${ }^{15}$

हालॉकि समीक्षा में यह स्वीकार किया गया है कि बड़े पैमाने पर हड़ताल हुई कोई खास उपलब्धि नहीं हुई। गया में पुलिस आन्दोलन में काफी अस्तव्यस्तता थी। एक हवलदार को अभियुक्त बनाये जाने से अन्य पुलिसकर्मियों में काफी अक्रोश था। स्थानीय कम्युनिस्टों ने इसका राजनीतिक फायदा उठाया। स्थानीय कम्युनिस्ट राम भरोसा पान्डेय एवं अब्दुल रऊफ ने $24,3,47$ को पुलिस कर्मियों के सवाल पर एक आम सभा का आयोजन किया। इसी तरह प्रदेश टी० यू० सी० के सहायक सचिव हवीवुर्रहमान ने छात्र नेता कमता सिंह एवं ब्रज किशोर प्रसाद के साथ मिलकर परेड मैदान में $25,3,47$ को आम सभा आयोजित की। वक्ताओं ने तमाम पुलिसकर्मियो को हड़ताल पर जाने की सलाह दी। अगले दिन $26,3,47$ को कुछ कम्युनिस्ट नेताओं के नेतृत्व में पुंलिसकर्मियो का जुलुस निकाला गया। जुलूस में पुलिसकर्मी नारा लगा रहे थे "खून का बदला खून से लेगे" "बन्दूक का जवाव बन्दूक से देंगे।"14 बाद में कुछ कम्युनिस्ट नेताओं को गिरफ्तार कर लिया गया। इसका फयदा सी० एस० पी० वालों ने उठाने की कोशिश की मगर कोई खास सफलता नहीं मिली।

\section{काँग्रेस को माउंटवेटन योजना स्वीकार, भारत को आजादी प्राप्त}

काँग्रेस और मुस्लिम लीग दोनों ने इस फैसले का स्वागत किया। देश पर अपनी पकड़ बनाये रखने के अंतिम प्रयास में ब्रिटिश साम्राज्यवादियों ने यह देखकर कि उन्हें भारत छोड़ना ही होगा, उसके विभाजन पर ही अपनी सारी शक्ति लगा दी। अप्रैल में माउंटबेटन योजना" की घोषणा की गयी। इसमें दो औपनिवेशिक राज्यों के रूप में भारत के विभाजन की व्यवस्था थी।

राष्ट्रीय काँग्रेस ने समझ लिया कि चाहे कुछ भी हो जाये, अँग्रेज मुस्लिम लीग के समर्थन से देश के टुकड़े करने पर तुले हुए है, 
इसलिए और अधिक रक्तपात से बचाने केलिये काँग्रेस मउंटवेटन योजना स्वीकार करने के लिए सहमत हो गयी।

जून 1947 में अखिल भारतीय काँग्रेस समिति के अधिवेशन ने ब्रिटिश प्रस्तावों को 61 के मुकाबले 157 मतों से स्वीकार कर लिया। ${ }^{16}$ अगस्त 1947 में ब्रिटिश संसद ने माउंटबेटन योजना का इंडीपेंस ऑफ इंडिया के रूप में अनुमोदन किया जो उसी वर्ष 15 अगस्त को लागू हो गया।

भारतीय कम्युनिस्ट पार्टी की बिहार प्रदेश समिति ने काँग्रेस एवं अन्य देशभक्त संगठनों के साथ 15 अगस्त 1947 को "प्रथम स्वाधीनता दिवस" धूमधाम से मनाने का निश्चय किया। समिति ने इसके लिए कई कार्मो की ओर कार्यकर्त्ताओं का ध्यान आकृष्ट किया $1^{17}$

- देश की पूरी एवं वास्तविक स्वतंत्रता की गारंटी,

- भारत से तमाम ब्रिटिश सेना की वापसी,

- अपने संविधान सभा द्वारा पारित व्यस्क चुनाव पद्धति के आधार पर राज्य की जनता द्वारा बहुमत से चुनी गयी उत्तरदायी सरकार का गठन,

- देश में पूरी तरह साम्प्रदायिक दंगों की समाप्ति,

- विरादराना राज्य पाकिस्तान के साथ दोस्ती एवं एकता का संबंध कायम करना,

- जमीदारी प्रथा की समाप्ती ,

- मजदूरों एवं किसानों की तत्कालीन मागों की पूर्ति।

- पार्टी ने पाकिस्तान बनने का समर्थन दिया था तथा उससे अच्छे संबंध की कामना की थी, जो पार्टी की भूल थी।

- पार्टी ने एक सप्ताह पूर्व का भी कार्यक्रम तय किया जो इस प्रकार से है :-

- 9 अगस्त से ही 15 अगस्त स्वाधीनता दिवस की तौयारी शुरू कर दी जाए।

- राष्ट्रीय झंडे की बड़े पैमाने पर बिक्री।

- प्रभात फेरियाँ निकाली जाये, यदि सेक्सन 144 लगा हुआ तो 4-4 साथियों का जत्था निकाला जाय।

\section{5 अगस्त के लिए पार्टी ने जो नारे ताय किये:}

- 15 अगस्त समारोह का आयोजन ब्रिटिश साम्राज्यवादियों पर राष्ट्रीय विजय की प्राप्ति।

- ब्रिटिश साम्राज्यवाद की हार को साम्राज्यवादियों की जड़ कटने के रूप में बदल डालो।

- तमाम ब्रिटिश शक्यियों (सेना सहित ) की वापसी।

- तमाम शक्तियाँ राज्य की जनता के हाथो।

- ब्रिटिश मालिकों के चाकर राजाओं की समाप्ति।

- जमींदारी प्रथा का पूरी तरह खात्मा।

- सभी के लिए जीवन भत्ते की गारंटी।

- हिन्दू-मुस्लिम भाई-भाई।

- नागरिक स्वतंत्रता की वापसी।

(1) 15 अगस्त 1947 को पार्टी द्वारा तय कार्यक्रम तमाम पार्टी कार्यालयों में राष्ट्रीय झंडे को फहराओ :-

पार्टी ने अपने कामरेडो के बीच इसकी व्याख्या करते हुए बताया कि "राष्ट्रीय झण्डे का फहराना "लाल झण्डे" का समर्पण करवाना नहीं है। अशोक चक्र अंकित नया तिरंगा किसी एक राजनीतिक पार्टी का झण्डा नहीं है, बल्कि यह राष्ट्रीय झण्डा है जो देश की सारी जनता की मनोभावना का प्रतीक है। इसलिए सभी पार्टी दफ्तरों पर इस राष्ट्रीय झण्डों को फहराकर देश की आय जनता की मनोभावना के साथ अपनी मनोभावना को व्यक्त करना चाहिए।"18

\section{(2) सामूहिक कार्यक्रम}

पार्टी ने अपनी सभी इकाइयों को निदेश दिया कि राष्ट्रीय झण्डोतोलन समारोह में धूमधाम से भाग लें। काँग्रेस के साथ संयुक्त समारोह का आयोजन हो राह हो या अकेले काँग्रेस द्वारा आयोजन हो उसमें पार्टी कार्यकर्ता भाग ले। प्रतिद्धंद्धिता के रूप में कोई कार्यक्रम न करें। संयुक्त जुलूस, प्रदर्शनों एवं आम सभाओं में राष्ट्रीय झण्डे के साथ भाग लें। धारा-144 हो तो कोई हंगामा नहीं करें।

\section{(3) आम सभा}

15 अगस्त की शाम को सभी स्थानों पर आम सभाओं का आयोजन करें। इन आम सभाओं में मजदूर-किसान को अपने नारों से लिखे पोस्टर एवं राष्ट्री झण्डे के साथ बुलायें। आम सभाओं में वक्ताओं द्वारा क्रमबद्ध रूप से पार्टी कार्यक्रम आम जनता को बतलाये जायें।

और फिर 15 अगस्त 1947 का दिन भी आ गया। रात्रि के 12 बजने में जब कुछ मिनट शेष थे, संविधान सभा के अध्यक्ष राजेन्द्र प्रसाद ने एक नये राज्य भारतीय संघ की स्थापना की उद्घोषणा की। सभी सदस्यों ने उठकर दो मिनट का मौन धारण करके अपने देशवासियों का पूण्य स्मरण किया, जिन्होंने मातृभूमि की स्वाधीनता के लिए अपने प्राण उत्सर्ग किये थे।

इसके बाद जवाहरलाल नेहरू पर आये, " बरसो पहले हमने भाग्य बधू से एक प्रतिज्ञा की थी, और अब वह समय आ रहा है, जब हम उस प्रतिज्ञा को समग्र रूप से या पूरी तौर पर न सही, तो काफी हद तक पूरा करेंगे। रात के 12 बजे, जबकि दुनिया नींद की गोद में होती है, भारत नये जीवन और स्वतंत्रता में प्रवेश करेगा। ...... इस पावन क्षण में हमें शपथ लेनी है कि तन-मन-धन से भारत और उसकी जनता की सेवा करेंगे। "19

15 अगस्त 1947 को अपराह्न में 4 बजे दिल्ली के ऐतिहासिक लाल किले के मैदान में एक विराट जन सभा हुई। लोगों का मानो सागर ही उमड़ आया था। किले के परकोटे पर स्वाधीनता संग्राम के नेतागण उपस्थित थे। वही कुछ हटकर भारतीय संघ के प्रथम गर्वनर जनरल लॉर्ड माउंटवेटन, उनके सलाहकार और सहायक भी बैठे थे। इकतीस तोपें दागकर सलामी दी गयी, सफेद शेरवानी और चूड़ीदार पाजामा पहने जवाहर लाल नेहरू अपनी जगह से उठकर ध्वज सतंभ के पास आये। उन्होंने ऊपर की ओर एक नजर डाली और अपनी संतोष भरी मुस्कान छिपा न सके। ध्वज स्तंभ खाली था। कल तक किले पर यूनियन जैक फहरा रहा था लेकिन शायद चालाक अँग्रेजों ने रात में उसे हटा दिया था, ताकि उसके उतारे जाने का अप्रिय दृश्य देखने से बच सकें। भारत के लोग जय जयकार के नारों से अपने प्रधानमंत्री का अभिवादन कर रहे थे। नेहरू ने धीरे-धीरे केसरिया, श्वेत और हरे रंगोवाला ध्वज उठाया और आकाश में स्वाधीन भारत का तिरगा फहराने लगा।

\section{निष्कर्ष}

अतः हम कह सकते है कि यद्यपि स्वतंत्रता प्राप्ति में काँग्रेस का बड़ा भारी हाथ था, परन्तु कई अन्य सहायक तत्व भी मौजूद थे। स्वतंत्रता-प्राप्ति के लिए जो कार्य कांग्रेस ने किया, वह अत्यन्त सतुल्य था परन्तु क्रान्तिकारियों और उग्रवादियों के त्यागों और बलिदानों को भूलना भी अनुचित होगा। उन्होंने भी ब्रिटिश सरकार के विरूद्ध ऐसे समय आन्दोलंन अपने-अपने ढ़ंग से किए जब सरकार बिल्कुल निरंकुश बन चुकी थी ओर कांग्रेस या तो आन्दोलंन करने के लिए तैयार नहीं थी या इसके आन्दोलंन अपर्याप्त सिद्ध हो चुके थे हमें स्वराज्यवादियों के त्यागों को भी न भूलना चाहिए। प्रेस, लेखकों, विद्यार्थियों, मजदूरों और साधारण जनता ने भी अपने-अपने ढ़ंग से सहायता दी। इसका प्रमाण यह है कि दूसरे विश्व युद्ध के बाद अंग्रेजों पंजे से भारत बल्कि वर्मा, लंका, मिरत्र साइप्रस मलाया नाइजीरिया और पश्चिमी दीप भी स्वतन्त्र हो गए हैं। 
स्वतंन्त्रता प्राप्ति के बाद भारत के संविधान को पूर्ण किया गया तथा शरणर्थियों के बसाने का कार्य किया गया। देश के विकास के लिए भारत सरकार ने पंचवर्षीय योजनाएँ बनाई। देशी रियासतो को भारतीय संघ में शामिल किया गया और एकता को नष्ट होने से बचाया गया। उनमें भी लोकतंत्र की स्थापना की गई। अंग्रेज जाते समय सर्वोच्चता को केन्द्रीय सरकार को नहीं दे गए थे, इसलिए बहुत से राज्य स्वतंत्र होना चाहते थे परन्तु सरदार बल्लभ भाई पटेल ने बड़ी चतुराई से काम लिया और उनको भारत के संविधान को मानने के लिए राजी कर लिया स्वतन्त्रता की प्राप्ति के बाद से भारत के पुनस्थान के लिए निरन्तर यत्न किया जा रहा है आशा है कि शीघ्र ही भारत उन्नति के शिखर पर पहुँच जाएगा।

भारतीय कम्युनिस्ट पार्टी ने भी पूरे देश में 15 अगस्त 1947 को प्रथम स्वाधीनता दिवस मनाया। बिहार में बड़े धूम-धाम एवं उल्लास के साथ स्वतत्रंता दिवस मनाया गया। गंगाधर दास के अनुसार "12 बजे रात में जब अजादी की घोषणा हुई तो बिहार राज्य पार्टी कार्यलय पर माइक लगाकर क्रांतिकारी एवं देशभक्ति गीतों को बजाना शुरू किया गया। हमलोगों ने "जनता का अब राज्य बनाओ " का नारा दिया।"21

इस तरह पूरे बिहार में स्वधीनता दिवस मनाया गया और इस प्रकार बर्षों से चल रही स्वाधीनता की लड़ाई का पटाक्षेप आजादी के रूप में हुआ।

बिहार में काफी धूम-धाम से स्वतंत्रता दिवस मनाया गया। 14 अगस्त की आधी रात को जयरामदास दौलतराम बिहार के राज्यपाल नियुक्त किए गए। भारतीय गणराज्य का संविधान बनाने के लिए राजेन्द्र प्रसाद की अध्यक्षता में सविधान सभा का गठन किया गया, जिसने ढ़ाई वर्षों में भारतीय गणराज्य का संविधान तैयार किया गया। वह संविधान 26 जनवरी, 1950 ई0 को संपूर्ण देश में लागू किया गया। $\left.\right|^{22}$

\section{संदर्भ}

1. कौलेश्वर राय, बिहार का इतिहास, पृ०-263

2. वही पृ०-264

3. अयोध्या सिंह, भारत का मुक्ति सग्राम पृ०-774

4. श्री भोगेन्द्र झा से लिये गये साक्षात्कार का तथ्य।

5. वही

6. श्री भोला प्रसाद, भू० पू० एम0 पी० एवं कम्युनिस्ट पार्टी के बिहार राज्य नेता से 5 जून 1985 को बिहार राज्य पार्टी कार्यालय, अजय भवन, पटना में लिए गये साक्षात्कार लिया गया तथ्य।

7. फाईल न0 113 (11) 147- राजनीतिक विशेष, बिहार राज्य अभिलेखागार, पटना।

8. फाईल नं० 113 (4)/47, राजनीतिक विशेष विभाग, बिहार राज्य अभि०, पटना।

9. डी० आई० जी० अफसरों के $17: 2: 84$ की रिपोर्ट से लिया गया तथ्य, फाईल न0 113(3)147, राजनीतिक विशेष विभाग, बिहार राज्य अभिलेखागार, पटना।

10. फाईल न0 113 (111) 47 राजनीतिक विशेष विभाग, बिहार राज्य आभिलेखागार, पटना।

11. सी० आई०डी०, पटना, बिहार विशेष शाखा की रिपोर्ट के आधार पर फाईल नं0-113(111) 147 राजनीतिक विशेष विभाग बिहार राज्य अभिलेखागार, पटना

12. बिहार विशेष शाखा के गुप्तचर द्वारा 17 मार्च 1947 को जमशेदपुर से भेजी गयी रिपोर्ट से फाईल न0 113(4) 47, राजनीतिक विशेष विभाग, बिहार राज्य आभिलेखागार, पटना।

13. बिहार गुप्तचर विभाग द्वारा 10 अप्रेल 1947 को कम्युनिस्ट गतिविधियों के संबंध में तैयार समीक्षा फाईल नं०
113(11)/47 राजनीतिक विशेष विभाग, बिहार राज्य आभिलेखागार, पटना।

14. वही

15. बिहार गुप्तचर विभाग द्वारा 10 अप्रेल 1947 को कम्युनिस्ट गतिविधियों के संबंध में तैयार समीक्षा/फाईल नं० 113(11)/47, राजनीतिक विशेष, बिहार राज्य अभिलेखागार, पटना।

16. अतोनोवा, लेनिन कोतोत्सकी -भारत का इतिहास, पृ० 658 । 